\title{
The effects of salt and drought stress on phenolic accumulation in greenhouse-grown Hypericum pruinatum
}

\author{
Omer Caliskan, ${ }^{1}$ Jolita Radusiene, ${ }^{2}$ Kadir Ersin Temizel, ${ }^{3}$ Zydrunas Staunis, ${ }^{2}$ Cuneyt Cirak, ${ }^{1}$ \\ Dursun Kurt, ${ }^{1}$ Mehmet Serhat Odabas ${ }^{1}$ \\ ${ }^{1}$ Vocational High School of Bafra, Ondokuz Mayıs University, Samsun, Turkey; ${ }^{2}$ Nature Research Centre, \\ Institute of Botany, Vilnius, Lithuania; ${ }^{3}$ Department of Agricultural Structures and Irrigation, Ondokuz \\ Mayıs University, Samsun, Turkey
}

\begin{abstract}
Hypericum pruinatum is a medicinal herb containing several bioactive compounds with important pharmacological activity. In this study, we investigated the effects of the salt (0.03 - control, 1 , $2.5,4$ and $8 \mathrm{dS} \mathrm{m}^{-1}$ of $\mathrm{MgSO}_{4}, \mathrm{CaCl}_{2}$ and $\mathrm{NaCl}$ salts) and drought stress $(80,100$ and $120 \%$ of required water) on the content of phenolic compounds, namely chlorogenic acid, rutin, hyperoside, isoquercetine, quercitrine and quercetine in greenhouse grown plantlets. In general, the salt stress especially in elevating doses increased the levels of all of the compounds analysed, whereas drought stress did not cause a significant chance in chemical content of the plantlets. The present results indicated that abiotic stress factors, particularly salinity, have a marked influence on the content of phenolic constituents in H. pruinatum and it is a salt tolerant species. The results also indicated that phenolic compounds play a significant physiological role in salinity tolerance.
\end{abstract}

\section{Introduction}

Among the different environmental constraints, salt and

Correspondence: Omer Caliskan, Vocational High School of Bafra, University of Ondokuz Mayis, 55400, Bafra, Samsun, Turkey. Tel: +90-362-5426763 - Fax: +90-362-5426761.

E-mail: ocaliskan@omu.edu.tr

Key words: Salt; Drought stress; Phenolic accumulation; Greenhouse; Hypericum pruinatum.

Acknowledgements: this research was funded by a grant (No. MIP57/2010) from the Research Council of Lithuania. The research was performed in cooperation with the Ondokuz Mayis University, Turkey.

Received for publication: 13 January 2017.

Revision received: 30 March 2017.

Accepted for publication: 4 April 2017.

CCopyright O. Caliskan et al., 2017

Licensee PAGEPress, Italy

Italian Journal of Agronomy 2017; 12:918

doi:10.4081/ija.2017.918

This article is distributed under the terms of the Creative Commons Attribution Noncommercial License (by-nc 4.0) which permits any noncommercial use, distribution, and reproduction in any medium, provided the original author(s) and source are credited. drought stress are considered as important abiotic factors limiting plant growth and productivity especially in arid and semi-arid regions (Zhu, 2001). The detrimental effects of salinity on plant physiology are though to be associated with specific ion effect (salt stress), low water potential in soil solution (drought stress), nutritional imbalance, redirection of energy from growth to extracting pure water from the saline water and to produce defensive chemicals or a combination of these different factors (Munns and Tester, 2008). Results from recent studies in the past few years, however, have pointed out that sensitivity to salt stress is associated mainly with oxidative stress, which is also caused by drought stress and due to the disturbance in balance between the rates of production and elimination of reactive oxygen species (ROS) (Turkan and Demiral, 2009; Tounekti et al., 2011).

Plants have evolved different defence systems to avoid the oxidative damage caused by salt and drought stress including overproduction of antioxidant metabolites which stopping the propagation of oxidative chain reactions. In this case, polyphenolic compounds such as phenolic acids, flavonoids, proanthocyanidins and anthocyanins play an important role in reducing the detrimental effects of salinity (Hichem et al., 2009). The proven antioxidant activity of phenolics allows them to act as ROS scavenging agents. As a result, their synthesis is generally triggered in response to biotic/abiotic stresses and especially under salt stress conditions (Souza and Devaraj, 2010). Except for their role in reducing the detrimental effects of salinity and drought, phenolic compounds exhibit wide range of physiological properties such as antiallergic, antiatherogenic, anti-inflammatory, antimicrobial, antithrombotic ones (Balasundram et al., 2006). They have also defensive roles in protecting plants from biotic attacks by pathogens and herbivores (Conceicao et al., 2006).

The genus Hypericum L. comprises more than 450 species divided in 36 sections with worldwide distribution in warm temperate, subtropical and mountainous tropical regions (Robson, 2001). Herbs belonging to this genus are very important in pharmacology, particularly Hypericum perforatum $\mathrm{L}$. which has been studied deeply for the biologically activity of its extracts and isolated active components (Shelton, 2009). The pharmacological activities of Hypericum perforatum extracts namely, antidepressive and antiviral activities are mainly attributed to their flavonoid, hypericin and hyperforin contents (Avato, 2005). Turkey is an important center for Hypericum genus where it is represented by 89 species of which 43 are endemic (Bingol et al., 2011). Hypericum pruinatum Boiss. and Bal., a perennial herbaceous plant which grows naturally in igneous slopes at high altitudes is one of the species of Turkish Hypericum. In previous studies, H. pruinatum were reported to have great pharmaceutical potential, with its well-documented contents of hypericin (Cirak et al., 2006), hyperforin (Smelcerovic et al., 2008), organic acids and flavonoids (Cirak et al., 2007). Because of the similarities in the 
chemical compositions of $H$. perforatum and $H$. pruinatum, the latter species may eventually become a domesticated plant and serve as an alternative to $H$. perforatum for medicinal use.

Agronomic studies on all Hypericum species are rather low and the genus is quite understudied. Efforts undertaken to describe the effect of abiotic stress on chemical constituents of Hypericum plants are also very scarce and limited to those on Hypericum perforatum (Gray et al., 2003; Zobayed et al., 2007) and Hypericum brasiliense (Abreu and Mazzafera, 2005). In the previous studies, it was found that the drought stress greatly influenced the phenolic contents of both species of Hypericum. To the best of our knowledge, no study has been conducted concerning the changes of phenolic contents in $H$. pruinatum in response to abiotic stress. We investigate here for the first time the phenolic content of this species under salt and drought stress.

\section{Materials and methods}

\section{Plant material and culture conditions}

$H$. pruinatum plantlets were established from 5 months old seeds collected on approximately 30 plants representing the wild population from the Gümüş district of Amasya Province, Turkey $\left(41^{\circ} 04^{\prime} \mathrm{N} ; 36^{\circ} 01^{\prime} \mathrm{E}\right.$; $890 \mathrm{~m}$ a.s.1.). Plant samples were identified by Dr. Hasan Korkmaz, Department of Biology, University of Ondokuz Mayis, Samsun, Turkey. Voucher specimen was deposited in the herbarium of Ondokuz Mayis University Agricultural Faculty (OMUZF \# 107). Seeds were germinated in a float system, commonly used for seedling production of broad-leaves tobacco Burley and Flue-Cured-Virginia under a $16 \mathrm{~h}$ light: $8 \mathrm{~h}$ dark cycle. Newly emerged seedlings were transferred to pots, $30 \mathrm{~cm}$ in diameter (7L), filled with the mixture of commercial torf Tray Substrate and soil (35\% sand, $45 \%$ silt and $20 \%$ clay) in $1: 3$ rate $(\mathrm{w} / \mathrm{w})$. The pots were watered daily until they reached full flowering at which chemical accumulation was reported to be highest for $H$. pruinatum (Cirak et al., 2014b, 2015). Main chemical and physical properties of the peat are shown in Table 1. After maturation, the threemonth-old plantlets were moved to greenhouse conditions $(16 / 8 \mathrm{~h}$ light/darkness, $25^{\circ} \mathrm{C}$ temperature, $75 \%$ relative humidity, and 400 $\mu \mathrm{mol} \mathrm{m} \mathrm{m}^{-2} \mathrm{~s}^{-1}$ PAR).

\section{Abiotic stress experiments}

City water supply (ECi: $0.03 \mathrm{dS} \mathrm{m}^{-1}$ ) was used as irrigation during experiment. The salts $\mathrm{MgSO}_{4}, \mathrm{CaCl}_{2}$ and $\mathrm{NaCl}$ at doses of 0.03 (control), 1, 2.5, 4 and $8 \mathrm{dS} \mathrm{m}^{-1}$ were used for salt stress experiment. Sodium adsorption ratio (SAR) was kept about 1 in all salinity levels so that only effect of salinity could be evaluated without any negative effect of sodium accordingly the below equation. In order to determine the amount of chemical materials added to water a computer programme based on Visual Basic was used (Yurtseven and Baran, 2000):

$$
S A R=\frac{\mathrm{Na}^{+}}{\sqrt{\frac{\mathrm{Ca}^{++}+\mathrm{Mg}^{++}}{2}}}
$$

The doses were selected from the previous publications (Yurtseven and Baran, 2000; Ozturk et al., 2004) and applied in three levels of water availability. Firstly control pots were watered with city water supply fully and left to leak. Then the amount of irrigation water not leaked but hold by pots was determined after leaks as the required water (RW). Thus, a total of 3 water amounts 80,100 and $120 \%$ of RW, respectively were used when half of the pot water holding capacity was over for drought stress experiment. The salt doses with different levels of water availability were applied 13 times in accordance with the allowed depletion. The experimental design was a factorial experiment in completely randomised plots with 3 replications, each consisting of 5 pots (Cirak et al., 2005, 2014a). Plantlets were harvested at the end of $39^{\text {th }}$ day of experiment when severe wilting was observed in pots treated with higher salt doses. After dried at room temperature, the harvested aerial parts were assayed for phenolic contents by HPLC.

\section{Preparation of plant extracts and high-performance liquid chromatography analysis}

Air-dried plant material was mechanically ground with a laboratory mill to obtain a homogenous drug powder. Samples of about $0.5 \mathrm{~g}$ (weighed with $0.0001 \mathrm{~g}$ precision) were extracted in $50 \mathrm{~mL}$ of $100 \%$ methanol by ultrasonication at $40^{\circ} \mathrm{C}$ for $30 \mathrm{~min}$ in a Sonorex Super model RK $225 \mathrm{H}$ ultrasonic bath. The prepared extracts were filtered through a membrane filter with pore size of $0.22 \mu \mathrm{m}$ (Carl Roth GmbH, Karlsruhe, Germany) and kept in a refrigerator $\left(+4^{\circ} \mathrm{C}\right)$ until analysis no longer than 3 hours.

A Shimadzu Prominence LC-20A (Shimadzu Europa GmbH, Duisburg, Germany) chromatographic system equipped with two LC-20AD model pumps, a SIL-20AC auto-injector, a thermostat CTO-20AC and a SPD-M20A detector was used for HPLC analysis. Separation of all compounds was carried out using an YMC Pack Pro-C18 (YMC Europe GmbH, Dinslaken, Germany) column $(150 \mathrm{~mm} \times 4 \mathrm{~mm}$ i.d.; $3 \mu \mathrm{m}$ particle sizes $)$ with $10 \mathrm{~mm}$ guardprecolumn. The mobile phase consists of solvent A [water containing $0.1 \%$ trifluoroacetic acid (TFA)] and solvent B (acetonitrile containing $0.1 \%$ TFA). The following binary gradient elution program was used: $0-1 \mathrm{~min}$ (B $5 \rightarrow 5 \%$ ), 1-14 $\min$ (B $5 \rightarrow 20 \%$ ), 14-20 $\min (\mathrm{B} 20 \rightarrow 80 \%), 20-30 \min (\mathrm{B} 80 \rightarrow 100 \%), 30-39 \min (\mathrm{B}$ $100 \rightarrow 100 \%$ ), 39-39.5 $\min (\mathrm{B} 100 \rightarrow 5 \%$ ), $39.5-45 \min (\mathrm{B} 5-5 \%)$.

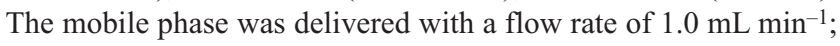
volume of extract injected was $10 \mu \mathrm{L}$ (Cirak et al., 2016).

Table 1. Main chemical and physical properties and average amount of added nutrients for the commercial peat tray substrate.

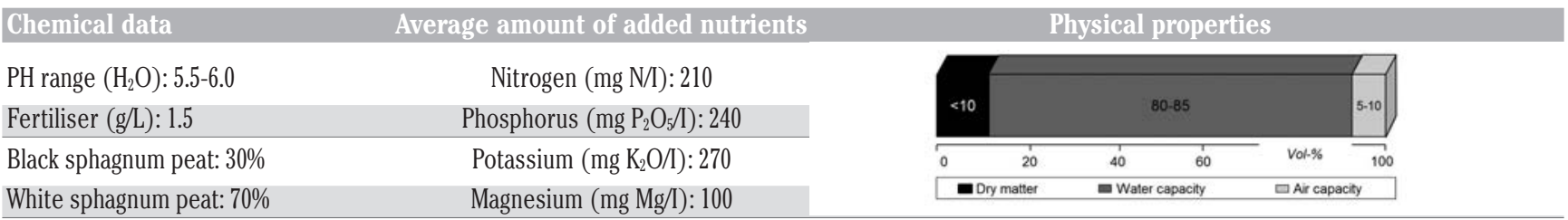


Detection was performed at $210-790 \mathrm{~nm}$ wavelength range with a constant column temperature at $40^{\circ} \mathrm{C}$. The eluted compounds were identified on the basis of their retention time by comparison with retention time of reference standards and also confirmed with UV spectra's of reference standards in the wavelength range from 210 to $790 \mathrm{~nm}$.

The quantification of detected compounds was achieved by using external standard method at the maximal absorption on the UV spectra of corresponding compounds: chlorogenic acid - 325 $\mathrm{nm}$, rutin $-353 \mathrm{~nm}$, hyperoside $-353 \mathrm{~nm}$, isoquercetine $-353 \mathrm{~nm}$, quercitrine $-347 \mathrm{~nm}$ and quercetine - $368 \mathrm{~nm}$ wavelengths. A sixpoint calibration curves were obtained with pure standards dissolved in $\mathrm{MeOH}$ in the concentration range of $0.2-110 \mu \mathrm{g} \mathrm{mL}^{-1}$. All calibration cures showed good linear regression $\left(r^{2}>0.999\right)$ within the test range. All solvents and standards of reference substances were of HPLC grade and purchased from Roth Chemical Company (Karlsruhe, Germany). Results were expressed as mg/g DW content of each tested compound which was calculated by multiplication of concentration and the plant mass (Paulsen and Selmar, 2016).

\section{Data analysis}

The data for chlorogenic acid, rutin, hyperoside, isoquercetine, quercitrine and quercetine contents of plant materials were objected to ANOVA. Differences among treatments were tested Duncan Multiple Range Test $(\mathrm{P}<0.01)$.

\section{Results and discussion}

Salt treatments resulted in wilting during time course of experiment and plant mortality was observed in several pots treated with $8 \mathrm{dS} \mathrm{m}^{-1}$ of salt as a result of severe wilting (Figure 1). The treatments, especially in increasing doses, also resulted in significantly higher phenolic production $(\mathrm{P}<0.01)$ and their positive effect on phenolic accumulation was more evident in decreasing water availability. Salt treated plantlets produced significantly higher content of chlorogenic acid, rutin, hyperoside, isoquercetine, quercitrine and quercetine in the presence of $80 \%$ of RW when compared to the plantlets treated with the same doses of salt but watered with 100 and $120 \%$ of RW. Quercetine content was the highest in plantlets treated with $8 \mathrm{dS} \mathrm{m}^{-1}$ of salt and watered with $80 \%$ of RW $(2.08 \mathrm{mg} / \mathrm{g} \mathrm{DW})$ and $100 \%$ of RW (1.94 mg/g DW) while moderate concentrations of salt treatments produced the highest contents of the other tested phenolic compounds. At the level of $80 \% \mathrm{RW}$, it is clear that both factors tested affected the chemical content of plants. It can be concluded that this water application further increased the salinity effect. In case of $100 \%$ RW application, drought stress did not occur but only salt stress was observed. The effect of salinity at $120 \%$ RW was minimal because of leaching.

The treatment of $4 \mathrm{dS} \mathrm{m}^{-1}$ of salt plus $80 \%$ of RW culminated in the highest content of chlorogenic acid $(8.36 \mathrm{mg} / \mathrm{g} \mathrm{DW})$, rutin $(2.99 \mathrm{mg} / \mathrm{g} \mathrm{DW})$ and quercitrine $(1.34 \mathrm{mg} / \mathrm{g} \mathrm{DW})$ accumulations, followed by $2.5 \mathrm{dS} \mathrm{m}^{-1}$ plus $80 \%$ of RW treatment $(8.31,2.79$ and $1.21 \mathrm{mg} / \mathrm{g}$ DW chlorogenic acid, rutin and quercitrine, respectively). Similarly, plantlets treated with 2.5 and $4 \mathrm{dS} \mathrm{m}^{-1}$ of salt and watered with $80 \%$ of RW accumulated the highest content of hyperoside (10.11 and $10.05 \mathrm{mg} / \mathrm{g} \mathrm{DW}$, respectively) and isoquercetine (13.12 and $12.62 \mathrm{mg} / \mathrm{g} \mathrm{DW}$, respectively). On the contrary, drought stress by oneself caused no morphological change in appearance and significant change in the chemical contents.
Control plantlets not salt treated but only watered with 80, 100 and $120 \%$ of RW produced similar content of chlorogenic acid, rutin, hyperoside, isoquercetine, quercitrine and quercetine (Figure 2).

Drought stress is one of the most important environmental stresses regulating plant growth and development and altering the main physiological and biochemical functions of plants. Drought stress is known to trigger the plant defense systems resulting in the enhanced production of secondary metabolites. In previous studies, the content of phenolic compounds namely, rutin, quercetin and total soluble phenols increased significantly in response to water and temperature stress in $H$. brasiliense (Abreu and Mazzafera, 2005) $H$. perforatum plants subjected to a brief drought stress showed an increase of quercetin and rutin (Gray et al.,

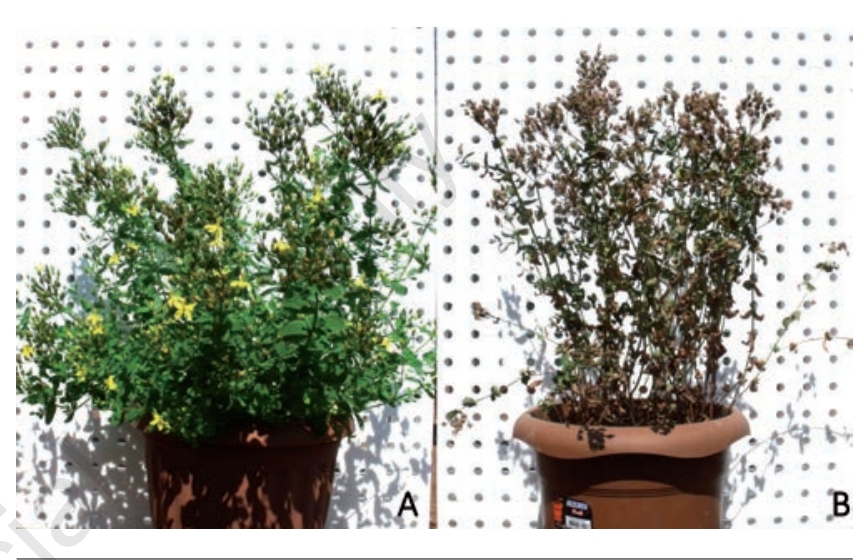

Figure 1. A view of control (watered with $100 \%$ of required water, A) and $8 \mathrm{dS} / \mathrm{m}$ salt treated (also watered with $80 \%$ of required water, B) Hypericum pruinatum plantlets at the end of the experiment.
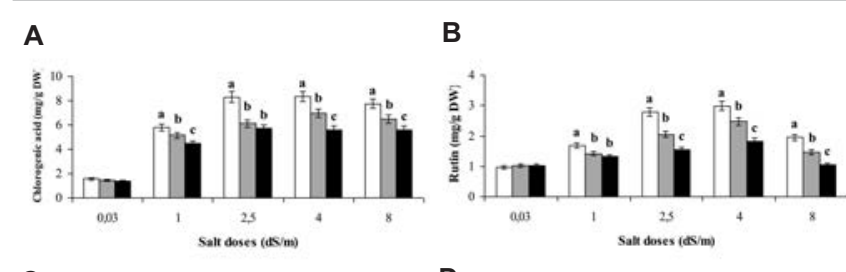

C

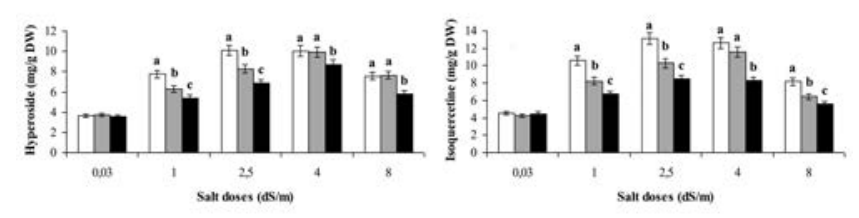

E

$\mathbf{F}$

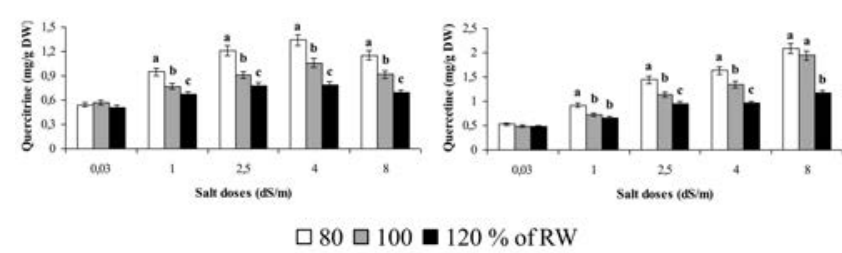

Figure 2. Chlorogenic acid (A), rutin (B), hyperoside (C), isoquercetine (D), quercitrine (E) and quercetine (F) contents of Hypericum pruinatum plantlets treated with different salt doses and water amounts (values with different small letters - a, b, cwithin columns for each dose of salt differ significantly at the level of $\mathbf{P}<0.01)$. 
2003). Similarly, hyperforin concentration of the same species increased significantly and was nearly double after 12 days of the drought stress treatment (Zobayed et al., 2007). On the contrary, drought stress by oneself did not change the chemical content of $H$. pruinatum in the present study. This phenomenon was probably related to the stress intensity because we used only 80, 100 and $120 \%$ of RW for drought stress experiment which were not sufficient to create the oxidative stress resulting in enhanced secondary metabolite production. During the onset and development of salt stress, the all major physiological processes are affected within a plant. Under saline conditions, plants have produced excess amount of ROS as a result of oxidative stress and if they are poorly protected, these reactive molecules may damage macromolecules such as DNA, proteins and membrane lipids resulting in cell death. The degree of oxidative cellular damage is controlled by the capacity for protection against oxidative agents (Chinnusamy et al., 2005; Plaza et al., 2009). The ROS scavenging ability of plants mainly depends on the antioxidant defense system including nonenzymatic components (Cuin and Shabala, 2008). Nonenzymatic components of the antioxidant defense system consist of various secondary metabolites, such as hydrophilic phenolics and flavonols, organic acids, lipophilic carotenoids, and watersoluble ascorbate and the enhancement of the phenolics metabolism is considered one of the responses to abiotic stresses (Close and McArthur, 2002). Phenolics are well-known antioxidant compounds having powerful radical scavenging ability and the distinct increase in phenolic content of plant tissues under salinity is thought to be involved in the prevention of stress-induced oxidative damage (Bourgou et al., 2010). It has been shown that salt stress induced disturbances in the secondary metabolic pathways, leading to an increase in phenolic compounds (Ksouri et al., 2007). In the present study, accordingly, chlorogenic acid, rutin, hyperoside, isoquercetine, quercitrine and quercetine contents of $H$. pruinatum plantlets increased significantly with elevating doses of salt treatment. The observed increase in phenolic content in the present study was possibly due to the antioxidative mechanisms in response to oxidative stress induced by salt stress conditions because the phenolic enhancing effect of salinity was more distinct in limited water availability. However it should be noted that The ROS produced in the course of drought and salt stress, are detoxified by several antioxidants from the photosynthetic electron transport chain within the chloroplasts (Tounekti et al., 2011), but the compounds tested in the present study are located in the vacuole. Nevertheless, they indeed contribute to avoid ROS, since their biosynthesis significantly reduce the stress related over-reduced status which leads to the generation of ROS as reported by Kleinwächter and Selmar (2015) and Selmar and Kleinwächter (2013). Increase in phenolic content in different tissues under increasing salinity has also been reported in a number of plant species. Ahmed et al. (2009) reported that major phenolic compounds namely, tyrosol, hydroxytyrosol, the vanillic, caffeic, syringic, p-coumaric, ferulic acids and total phenol concentrations in virgin olive oil increased under saline water irrigation. Plaza et al. (2009) reported two fold higher accumulation of total flavonoid and phenols in Cordyline fruticosa leaves in response to increasing salinity gradient in irrigation water and concluded that high flavonoids, phenols and sugars contents in this species are more useful indicators for salt resistance. Similarly, the total phenolic content in leaves was significantly increased by moderate salt treatment with a maximum at $50 \mu \mathrm{M} \mathrm{NaCl}$ in Cynara cardunculus (Hanen et al., 2008). Ksouri et al. (2007) reported that salt-challenged halophyte Cakile maritima produced significanlty higher amount of polyphenol in its leaves. Souza and Devaraj (2010) reported that the total phenol content of the salt-stressed leaves exhibited a concentration-dependent increase from 100-400 $\mu \mathrm{M}$ $\mathrm{NaCl}$ during the first $24 \mathrm{~h}$ of exposure in hyacinth bean. In the medicinal herb Echinacea angustifolia, the salinity of the nutrient solution significantly enhanced the root contents of chlorogenic acid, cynarin and cichoric acid in hydroponically grown planlets (Montanari et al., 2008). However, our data are not in accordance with those of several previous publications. After treated with different levels of saline irrigation water $(0.39,1.56,3.13,4.69,6.25$, 7.81 and $9.38 \mathrm{dS} \mathrm{m}^{-1}$ ) consisting of $\mathrm{NaCl}, \mathrm{CaCl}_{2}$ and $\mathrm{MgCl}_{2}$ salts, total flavonoids and carotenoids content were significantly reduced in Calendula officinalis (Khalid and da Silva, 2010). Total phenolic contents of 5- and 7-day old plantlets treated with 10 and $50 \mu \mathrm{M}$ of $\mathrm{NaCl}$ were significantly decreased in radish sprouts (Yuan et al., 2010). Similarly, total phenolic content decreased by 30, 54, and $61 \%$ in response to 20,40 , and $60 \mu \mathrm{M} \mathrm{NaCl}$ treatments in Nigella sativa (Bourgou et al., 2010). The differential accumulation of phenolic fractions under different salt treatments in the plant species with different salinity resistance suggests that salt resistant species and varieties may employ phenolic compounds, especially phenolic acids and flavonoids differentially to adapt to contrasting salinities (Mahmoudi et al., 2010). This phenomenon was confirmed by Salah et al., (2011) who reported that The salt-tolerant Medicago ciliaris line TNC 1.8 was more efficient at managing salt-induced oxidative damage in leaves and in roots than the saltsensitive line TNC 11.9, by preserving higher phenolic compound levels in both organs. In sugarcane and maize, similarly, salt tolerant varieties were found to accumulate significantly higher amount of soluble phenolics, anthocyanins, flavones and several polyphenols under salt stress conditions while content of the same metabolites decreased in response to salt treatment in case of salt sensitive varieties of both species (Wahid and Ghazanfar, 2006). Based on the results those authors pointed out the enhanced phenolic production in plant tissues under salt stress conditions as good indicator for salt resistance. The decrease in phenolic content of the aforasaid plant species in response to salt treatments could probably be due to their sensitivity to saline.

\section{Conclusions}

In conclusion, our results show that abiotic stress factors, particularly salinity, have a marked influence on the content of phenolic constituents in H. pruinatum. The increase in the contents of the compounds analysed indicates this medicinal herb as a salt tolerant species and agrees with data in the literature reporting that this is probably a response to the generation of ROS. These results also support the idea that phenolic compounds play a significant physiological role in salinity tolerance. Further studies are needed for broad spectrum understanding the roles of those metabolites in various plant species under saline conditions.

\section{References}

Abreu IN, Mazzafera P, 2005. Effect of water and temperature stress on the content of active constituents of Hypericum brasiliense Choisy. Plant Physiol. Biochem. 43:241-8.

Ahmed CB, Rouina BB, Sensoy S, 2009. Saline water urrigation effects on fruit development, quality, and phenolic composition of virgin olive oils, cv. Chemlali. J. Agric. Food Chem. 57:2803-11. 
Avato PA, 2005. Survey on the Hypericum genus: secondary metabolites and bioactivity. Stud. Nat. Product. Chem. 30:60334.

Balasundram N, Sundram K, Samman S, 2006. Phenolic compounds in plants and agri-industrial by-products: Antioxidant activity, occurrence, and potential uses. Food Chem. 99:191-203.

Bingol U, Cosge B, Gurbuz B, 2011. Hypericum species in flora of Turkey. Med. Arom. Plant Sci. Biotechnol. 5(Sp.Issue1):86-90.

Bourgou S, Bettaieb I, Saidani M, 2010. Fatty acids, essential oil, and phenolics modifications of black cumin fruit under $\mathrm{NaCl}$ stress conditions. J. Agric. Food Chem. 58:12399-406.

Chinnusamy V, Jagendorf A, Zhu JK, 2005. Understanding and improving salt tolerance in plants. Crop Sci. 45:437-48.

Cirak C, Aksoy HM, Ayan AK, Sağlam B, Kevseroğlu K, 2005. Enhanced hypericin production in Hypericum perforatum and Hypericum pruinatum in response to inoculation with two fungal pathogens. Plant Prot. Sci. 41:109-14.

Cirak C, Sağlam B, Ayan AK, 2006. Morphogenetic and diurnal variation of hypericin in some Hypericum species from Turkey during the course of ontogenesis. Biochem. Syst. Ecol. 34:1-13.

Cirak C, Radusiene J, Aksoy HM, Mackinaite R, Stanius Z, Çamaş N, Odabaş MS, 2014a. Differential Phenolic Accumulation in two Hypericum Species in response to Inoculation with Diploceras hypericinum and Pseudomonas putida. Plant Prot. Sci. 50:119-28.

Cirak C, Radusiene J, Ivanauskas L, Jakstas V, Çamaş N, 2014b. Phenological changes in the chemical content of wild and greenhouse-grown Hypericum pruinatum: Flavonoids. Turkish J. Agric. Forest. 38:362-70.

Cirak C, Radusiene J, Ivanauskas L, Jakstas V, Çamaş N, Kurt D, 2015. Phenological changes in the chemical content of wild and greenhouse-grown Hypericum pruinatum: hypericins, hyperforins and phenolic acids. J. Botany 4:37-47.

Cirak C, Radusiene J, Jakstas V, Ivanauskas L, Seyis F, Yayla F, 2016. Secondary metabolites of seven Hypericum species growing in Turkey. Pharm. Biol. 54:2244-53.

Cirak C, Radusiene J, Janulis V, 2007. Chemical constituents of some Hypericum species growing in Turkey. J. Plant Biol. 50:632-5.

Close DC, McArthur C, 2002. Rethinking the role of many plant phenolics protection from photodamage not herbivores? Oikos 99:166-72.

Conceicao LFR, Ferreres F, Tavares RM, 2006. Induction of phenolic compounds in Hypericum perforatum L. cells by Colletotrichum gloeosporioides elicitation. Phytochemistry 67:149-55.

Cuin TA, Shabala S, 2008. Compatible solutes mitigate damaging effects of salt stress by reducing the impact of stress-induced reactive oxygen species. Plant Signal Behav. 3:207-8.

Gray DE, Pallardy SG, Garrett HE, 2003. Effect of acute drought stress and time of harvest on phytochemistry and dry weight of St. John's wort leaves and flowers. Planta Med. 69:1024-30.

Hanen F, Ksouri R, Megdiche W, 2008. Effect of salinity on growth, leaf-phenolic content and antioxidant scavenging activity in Cynara cardunculus L. In: Abdelly C, Öztürk M, Ashraf M and Grignon $\mathrm{C}$ (eds). Biosaline agriculture and high salinity tolerance. Birkhäuser Verlag, Switzerland, pp. 335-43.

Hichem H, Mounir D, Naceur EA, 2009. Differential responses of two maize (Zea mays L.) varieties to salt stress: Changes on polyphenols composition of foliage and oxidative damages. Ind. Crop Prod. 30:144-51.

Khalid KA, da Silva JAT, 2010. Yield, essential oil and pigment con- tent of Calendula officinalis L. flower heads cultivated under salt stress conditions. Sci. Hortic. 126:297-305.

Kleinwächter M, Selmar D, 2015. New insights explain that drought stress enhances the quality of spice and medicinal plants: potential applications. Agron. Sustain. Dev. 35:121-31.

Ksouri R, Megdiche W, Debez A, 2007. Salinity effects on polyphenol content and antioxidant activities in leaves of the halophyte Cakile maritima. Plant Physiol. Biochem. 45:244-9.

Mahmoudi H, Huang J, Gruber MY, 2010. The impact of genotype and salinity on physiological function, secondary metabolite accumulation, and antioxidative responses in lettuce. J. Agric. Food Chem. 58:5122-30.

Montanari M, Deglnnocenti E, Maggini R, 2008. Effect of nitrate fertilization and saline stress on the contents of active constituents of Echinacea angustifolia DC. Food Chem. 107:1461-6.

Munns R, Tester M, 2008. Mechanisms of salinity tolerance. Annu. Rev. Plant Biol. 59:651-81.

Ozturk A, Unlukara A, Ipek A, 2004. Effects of salt stress and water deficit on plant growth and essential oil content of lemon balm (Melissa officinalis L.). Pak. J. Bot. 36:787-92.

Paulsen J, Selmar D, 2016. The difficulty of correct reference values when evaluating the effects of drought stress: a case study with Thymus vulgaris. J. Appl. Bot. Food Qual. 89:287-9.

Plaza BM, Jimenez S, Segura ML, 2009. Physiological stress caused by salinity in Cordyline fruticosa and its indicators. Commun. Soil Sci. Plant. 40:473-84.

Robson NKB, 2001. Studies in the genus Hypericum L. (Guttiferae). Bull. Br. Mus. (Nat. Hist.) Bot. 8:55-226.

Salah IB, Mahmoudi H, Gruber M, 2011. Phenolic content and antioxidant activity in two contrasting Medicago ciliaris lines cultivated under salt stress. Biologia 66:813-20.

Selmar D, Kleinwächter M, 2013. Stress enhances the synthesis of secondary plant products: the impact of stress-related overreduction on the accumulation of natural products. Plant Cell Physiol. 54:817-26.

Shelton RC, 2009. St John's Wort (Hypericum perforatum) in major depression. J. Clin. Psychiat. 70:23-7.

Smelcerovic A, Zuehlke S, Spiteller M, 2008. Phenolic constituents of 17 Hypericum species from Turkey. Biochem Syst Ecol. 36:316-9.

Souza MRD, Devaraj VR, 2010. Biochemical responses of Hyacinth bean (Lablab purpureus) to salinity stress. Acta Physiol. Plant. 32:341-53.

Tounekti T, Vadel AM, Onate M, Khemira H, Munne-Bosch S, 2011. Salt-induced oxidative stress in rosemary plants: damage or protection? Environ. Exp. Bot. 71:298-305.

Turkan I, Demiral T, 2009. Recent developments in understanding salinity tolerance. Environ. Exp. Bot. 67:2-6.

Wahid A, Ghazanfar A, 2006. Possible involvement of some secondary metabolites in salt tolerance of sugarcane. J. Plant. Physiol. 163:723-30.

Yuan G, Wang X, Guo R, 2010. Effect of salt stress on phenolic compounds, glucosinolates, myrosinase and antioxidant activity in radish sprouts. Food Chem. 121:1014-9.

Yurtseven E, Baran HY, 2000. The effects of irrigation water salinity and irrigation water amounts on yield and total mineral residues of broccoli (Brassica oleracea botrytis). Turk. J. Agric. For. 24:185-90.

Zhu JK, 2001. Plant salt tolerance. Trends Plant Sci. 6:66-71.

Zobayed SMA, Afreen F, Kozai T, 2007. Phytochemical and physiological changes in the leaves of St. John's wort plants under a drought stress condition. Environ. Exp. Bot. 59:109-16. 